\title{
Modeling and Simulation of multi-pulse Cycloconvereter-fed AC induction motor and study of output power factor
}

Rezgar Mohammed Khalil

B.Sc. \& M.Sc.
Maamoon Al-Kababjie

Ph.D.

\section{Electrical Engineering}

\begin{abstract}
Rizgarkhalil@yahoo.com
Al_kababjie@yahoo.com

Abstract

The need for use of cycloconverters is in controlling a.c motors at low speed drive especially in high power application. The MATLABSIMULINK model for three pulse, six pulse and twelve pulse three phase to three phase cycloconverter has been constructed. The control strategy of supplying the firing pulses is based on the cosine wave crossing method. The SIMULINK model for the control circuits to perform the procedure of this strategy has been constructed. A control circuit for each thyristor to control its firing pulses has been constructed separately to prevent any complexity in the control circuit. An R-L load was used. In additional a three phase induction motor has been connected to test the reliability of the system in controling the output frequency and then the motor speed. The present study includes circulating current and semicirculating current modes of operation with study of measuring and correction of output power factor of the cycloconverter and output voltage waveform harmonics.
\end{abstract}

Keywords:Three-phase to Three-phase, Cycloconvereter, Modeling and Simulation, MATLAB-SIMULINK model

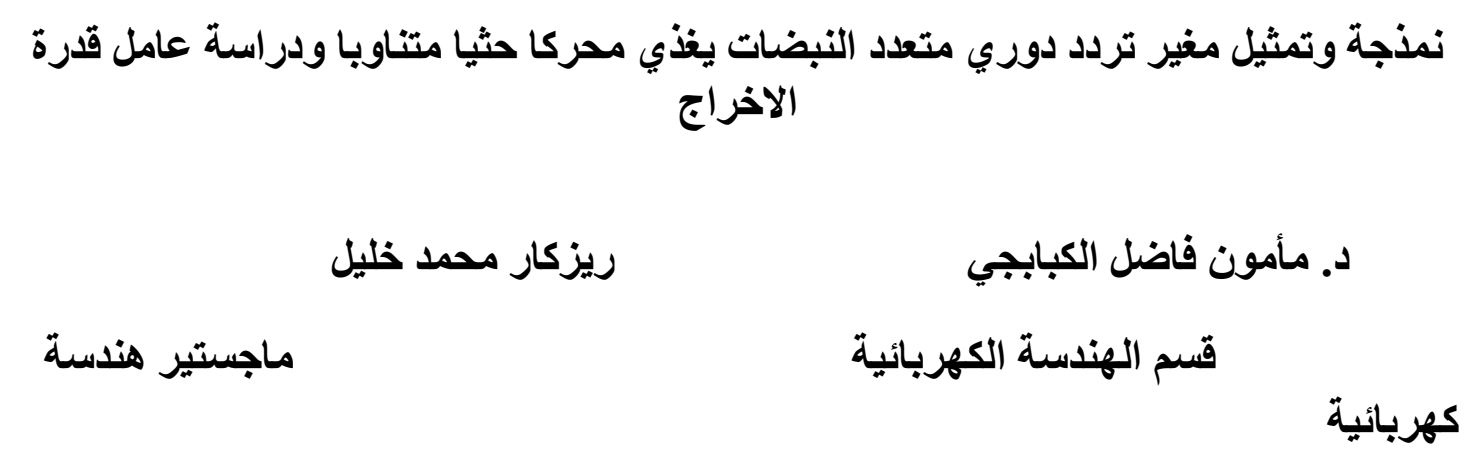


إن الحاجة إلى استخدام مغير التردد الدوري هي في السيطرة على المحركات المتناوبة

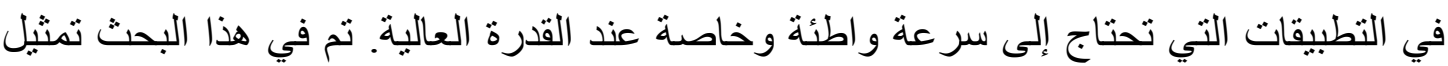

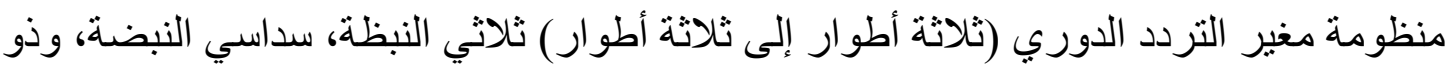

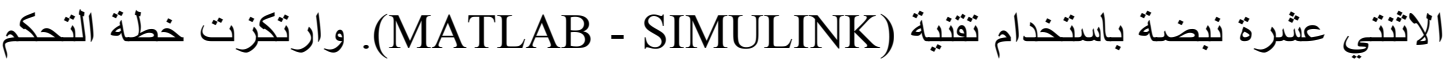

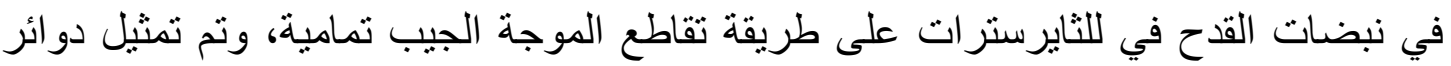

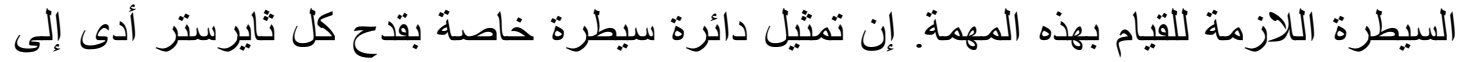

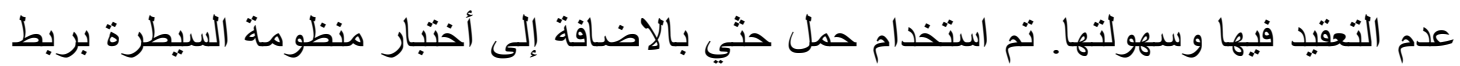

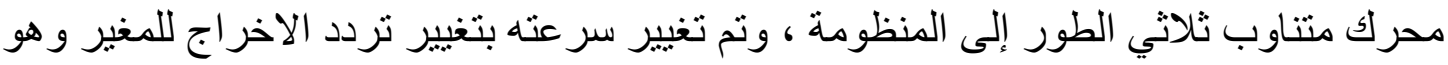

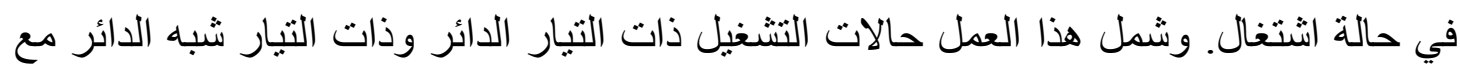

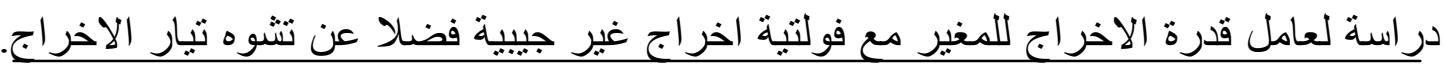

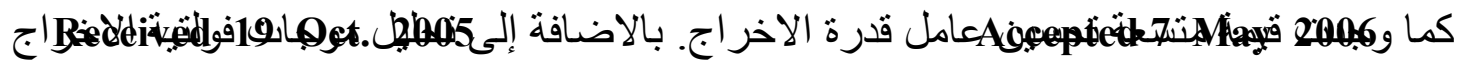

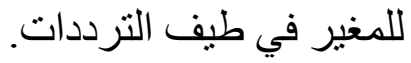

\section{1-Introduction:}

Frequency changers is an expanding field of power conversion technology. The increasing utilization of a.c motors in variable speed drives and the generation of electrical power from variable speed sources are examples of this field applications. Early systems of frequency changers incorporated rotating machines. These systems have been largely supplanted by static frequency changers using power semiconductor devices.

Static frequency changers can be broadly classified into two types: the First employ an intermediate d-c lin $k$ which consist of rectification of a-c power to d-c and then inversion the d-c power to a-c at variable frequency. The second type performs the power converting function in a single stage without any intermediate d-c link. That is mean the a-c supply frequency is converted directly to another frequency. The cycloconverter is a member of the second class[1].

Cycloconverters are suitable for large a-c machines because it has advantages: it has high efficiency owing to the simple construction of the main circuit, which consists, in its basic form, simply of an array of 
thyristor switches [5], and it is also naturally commutative, and no forced commutation circuits are necessary. As the same time it suffers from some disadvantages. It has a low maximum output frequency compared to the input frequency, and it suffers from voltage distortion. The application of a cycloconverter is rather limited, because the control circuit is often very complex, and therefore expensive[2].

One of the modern simulation software packages is SIMULINK, which is an extension of the popular MATLAB software. MATLAB SIMULINK is specially designed for simulating dynamic systems. It solves numerical problems in a fraction of time compared to other software packages, and it is more interactive than others.

In this work the MATLAB-SIMULINK packages have been used for modeling and simulating the cycloconverter system and its control circuits.

\section{2-The cycloconverter power circuit:}

The basic building block of a cycloconverter is the phase controlled converters. Anti-parallel combination of two such blocks forms one phase at the output. It is simply a dual converter as shown in fig.(2-1), which is controlled, through a time varying phase modulation of its firing pulses, so that it produces an alternating, rather than a direct, output voltage.

By appropriate control, it is possible to produce a continuous variation of both the amplitude and frequency of the output voltage wave.

The method of connecting the phase controlled converters governs their operation in three modes. These are the non-circulating, the circulating, and the semi-circulating current modes. Mainly, the output waveform is a function of the converters control algorithm. In practical application, the three-phase to three-phase cycloconverter is commonly required to derive a three-phase output from a three-phase input. The most logical method for producing a three-phase output, is to use three symmetrical independent, dual converters, one for each output phase. Fig(2-2) represents a three-phase to three-phase three-pulse cycloconverter. 
In order to control the output voltage of the phase-controlled converter or cycloconverter, it is necessary to control the phase of the thyristor firing pulses. Many alternatives exist for achieving this end. The task of a firing controller is to generate time-varying sequences of pulses for triggering the thyristor devices. In this work the control strategy is based on taking the natural sampling in corporating the cosine wave crossing control technique, which has been adequately explained with the cycloconverter operation in the well-known text book [1].

As in case of the rectifier or phase-controlled converter circuit, from the view point of reducing the external harmonic voltages and currents to a minimum, the pulse number of the cycloconverter circuit should be as high as possible. Fig(2-3) and (2-4) represents the diagram of three-phase to three-phase six-pulse and twelve pulse bridge cycloconverters respectevely. [1]

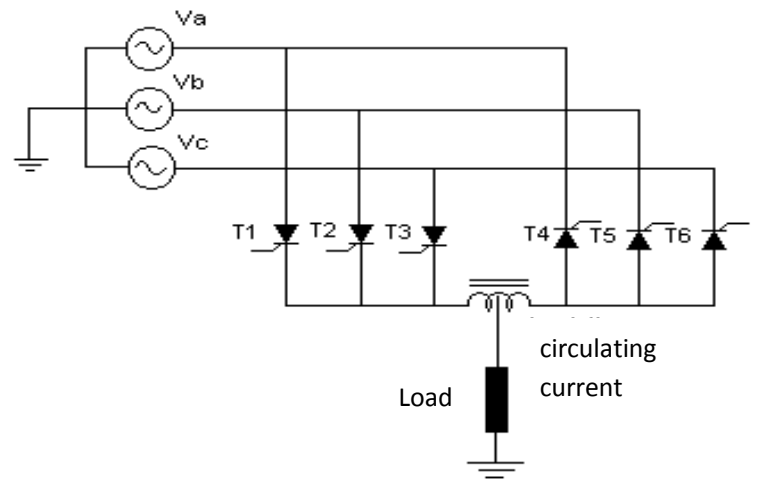

Fig (2-1): 3-pulse 3-phase to 1- phase dual converter

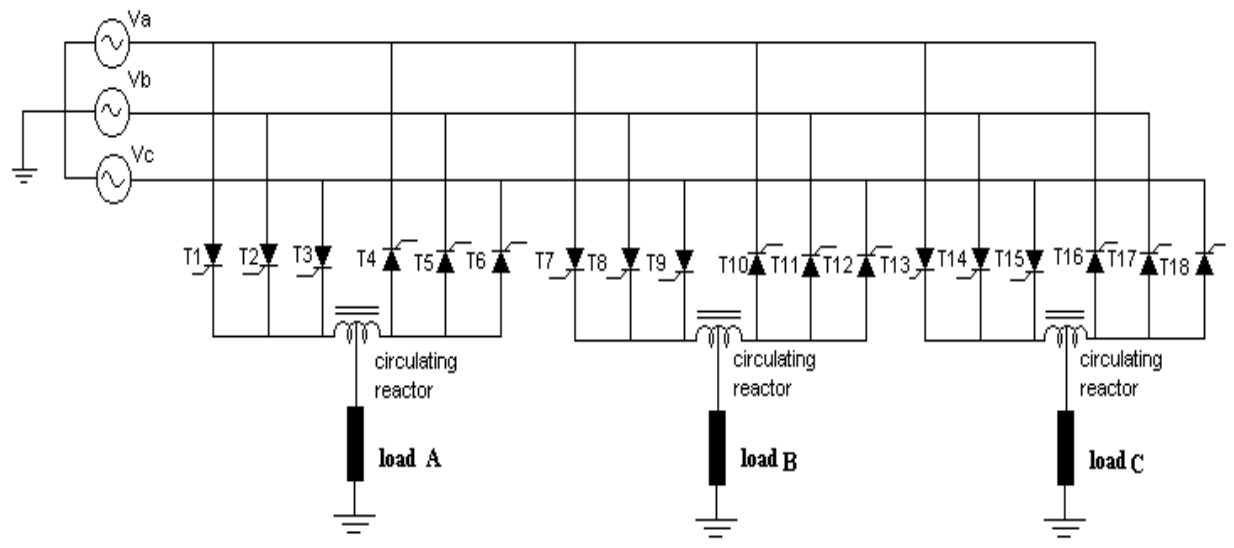


Fig (2-2): 3-pulse 3-phase to 3-phase cycloconverter

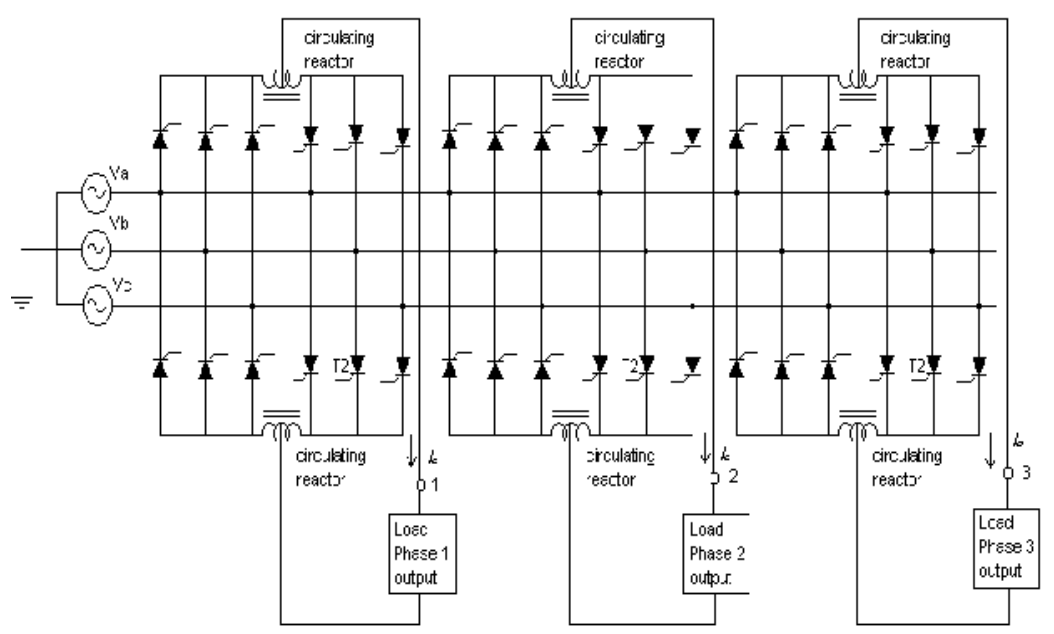


Fig (2-3): Six-pulse 3-phase to 3-phase bridge cycloconverter.

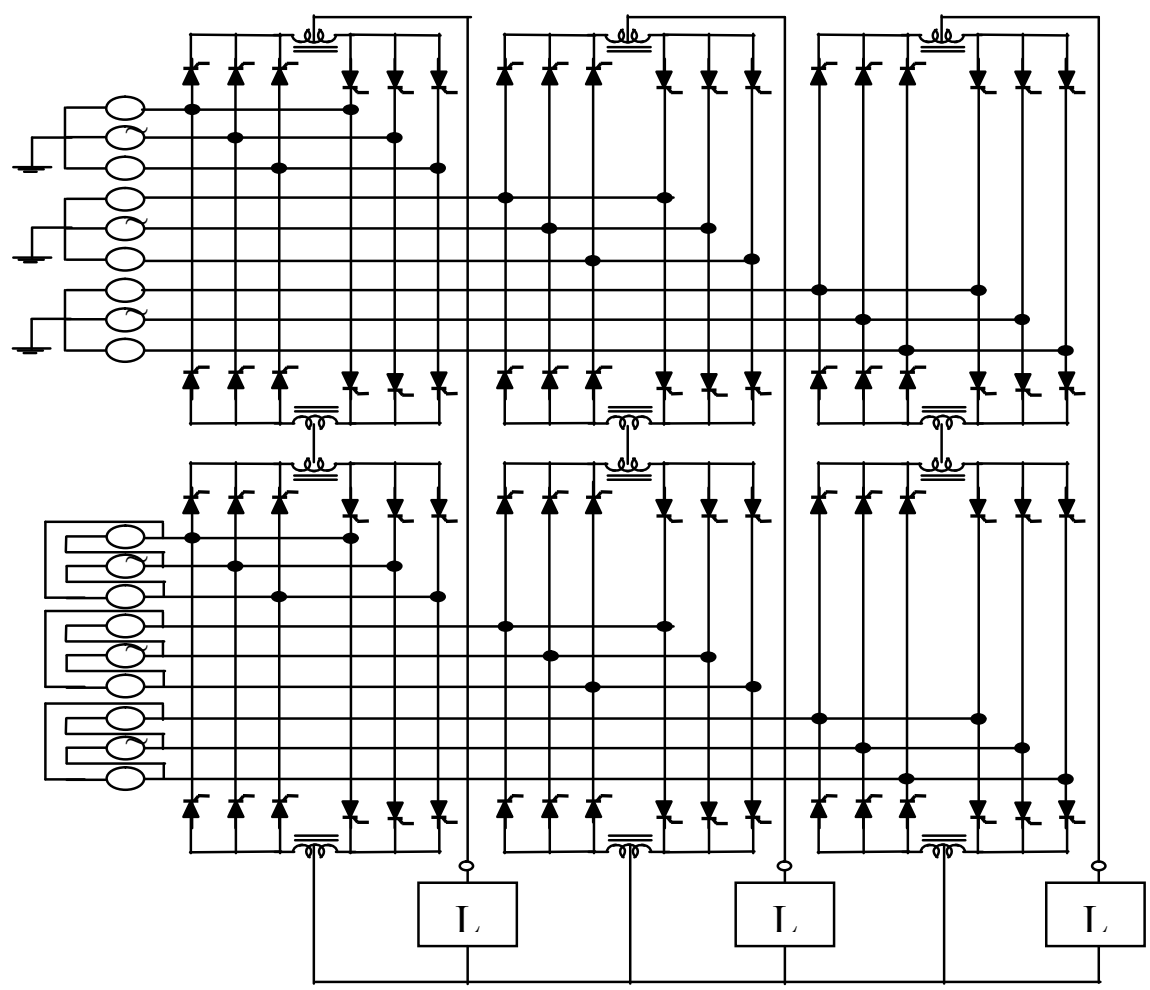


Fig (2-4): twelve-pulse 3-phase to 3-phase bridge cycloconverter.

\section{3-The MATLAB-SIMULINK model for three-phase to three-phase} cycloconverter:

Fig.(3-1) shows the MATLAB-SIMULINK model which has been constructed for the three-phase to three-phase six-pulse cycloconverter, on the same way model for twelve pulse cycloconverters has been performed These models will be explained in the following sections:

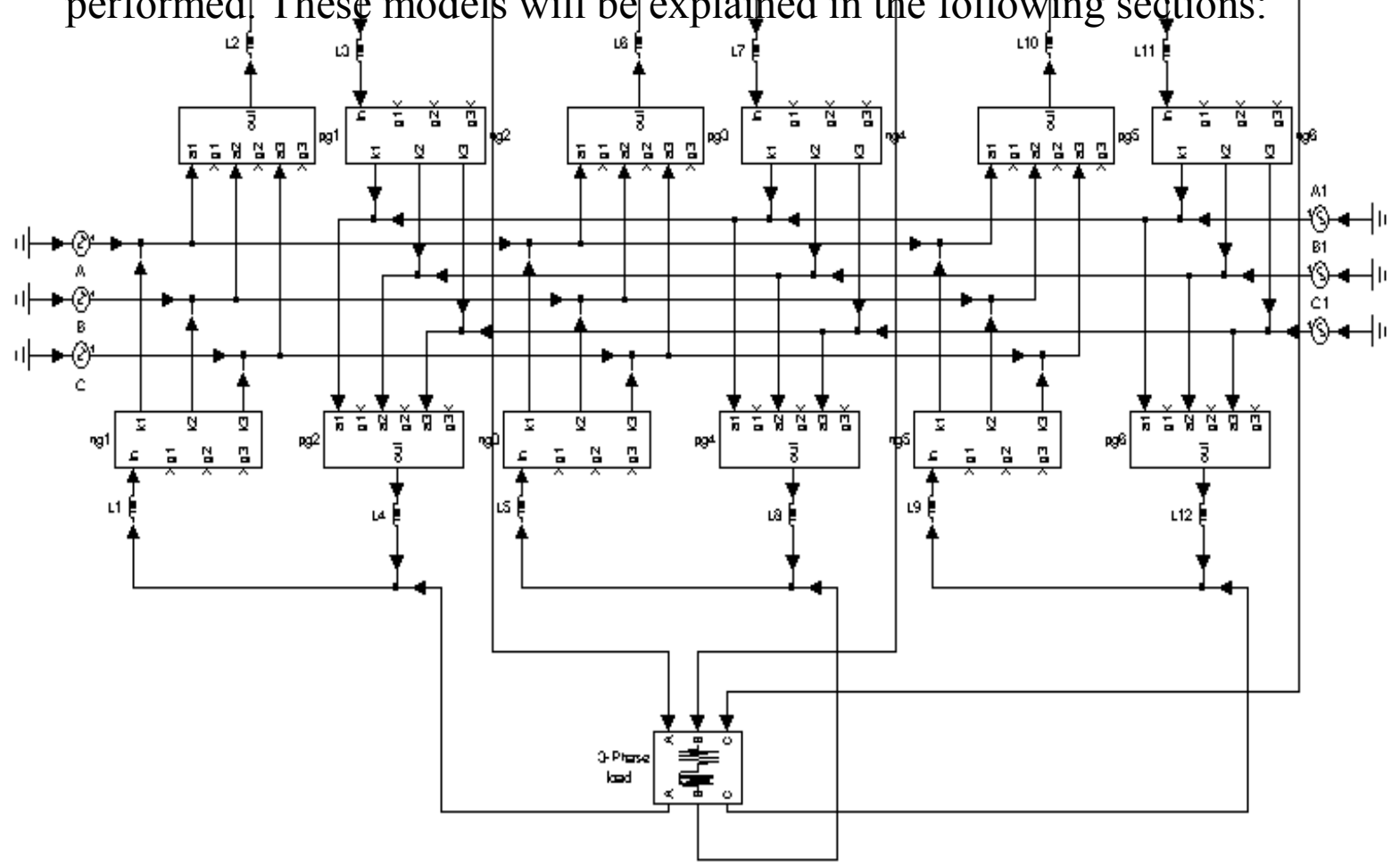




\section{Fig (3-1): The MATLAB-SIMULINK model for 6-pulse 3-phase to 3-phase cycloconverter}

\section{(3-1) Three-phase input supply:}

A number of pure sinusoidal single phase supply are formed to represent a double secondary output of three-phase transformer. Where first set represents the first secondary winding which shifted 30 degree to perform the zero crossing instant when using delta-star connection of three-phase transformer, and the second set represents the second windings, and it gives an inherently 180 degree phase shift between the input voltage waves for each converter. This makes the instants of starting a new timing waves, i.e. the instants of zero firing angle for the positive converter coincide with those of the negative converter. Which simplifies the control circuit model. In the case of 12-pulse cycloconverter, the input terminals of each of the 6 individual 6-pulse converters are fed from separate secondary windings on the input transformer. It should be noted that it is not permissible to use the same secondary winding for more than one converter. This is because each 12pulse converter, by itself, requires two completely isolated transformer secondary winding.

\section{(3-2) Dual-Converters:}

Six SIMULINK sub-systems represents six phase controlled converters has been constructed and indicated as pg and ng. Fig.(3-2) a, and $b$ shows the connection of thyristors in positive and negative converters respectively. 


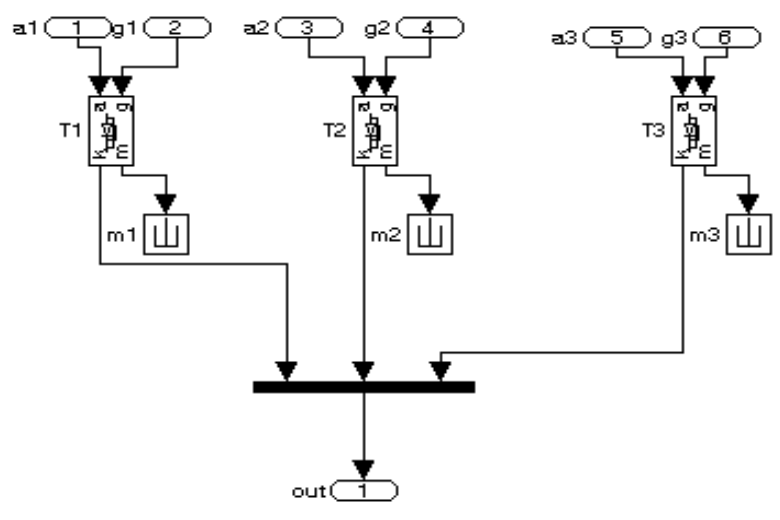

(a)

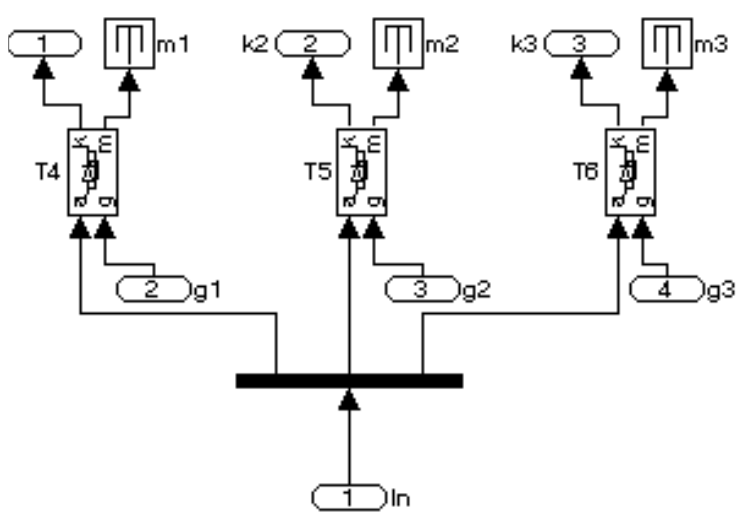

(b)

Fig (3-2): MATLAB-SIMULINK model for positive and negative converters respectively

\section{(3-3) The Control Circuit:}

As mentioned before the control strategy based on cosine wave crossing control method, so we will have three timing waves and three reference waves and a lot of intersection points, which means that the control circuit and control program will be very complex. To make this task more simple, and to obtain an online and variable control on the cycloconverter system, a SIMULINK model of control circuit for controlling the firing pulses of each thyristor has been constructed, i.e we have (18) control circuits for 3-pulse cycloconverter one for each thyristor and (36) circuits for 6-pulse cycloconverter and (72) circuits for 12-pulse cycloconverter.

Each control circuit based on generating the timing wave for the corresponding thyristor. On the other hand a separate sub-system for generating three-phase reference waves and distribute them on thyristors has been performed. So in each control circuit we have one timing wave and one reference wave, with appropriate monitoring for intersections at the wanted slope of the timing wave and passing adequate time and amplitude triggering pulse to the thyristor at the wanted intersections. For semi-circulating current mode of operation a closed loop control circuit will be needed, were the pulses from the positive and negative firing pulse generators are transmitted to the positive and negative conveters through gates. The control signals for these gates are respectively the 
output signals from the positive and negative current level detectors. Fig.(3-3) a and $b$ illustrates SIMULINK sub-system models of a single control circuit for circulating current and semi-circulating current modes of operation respectively.
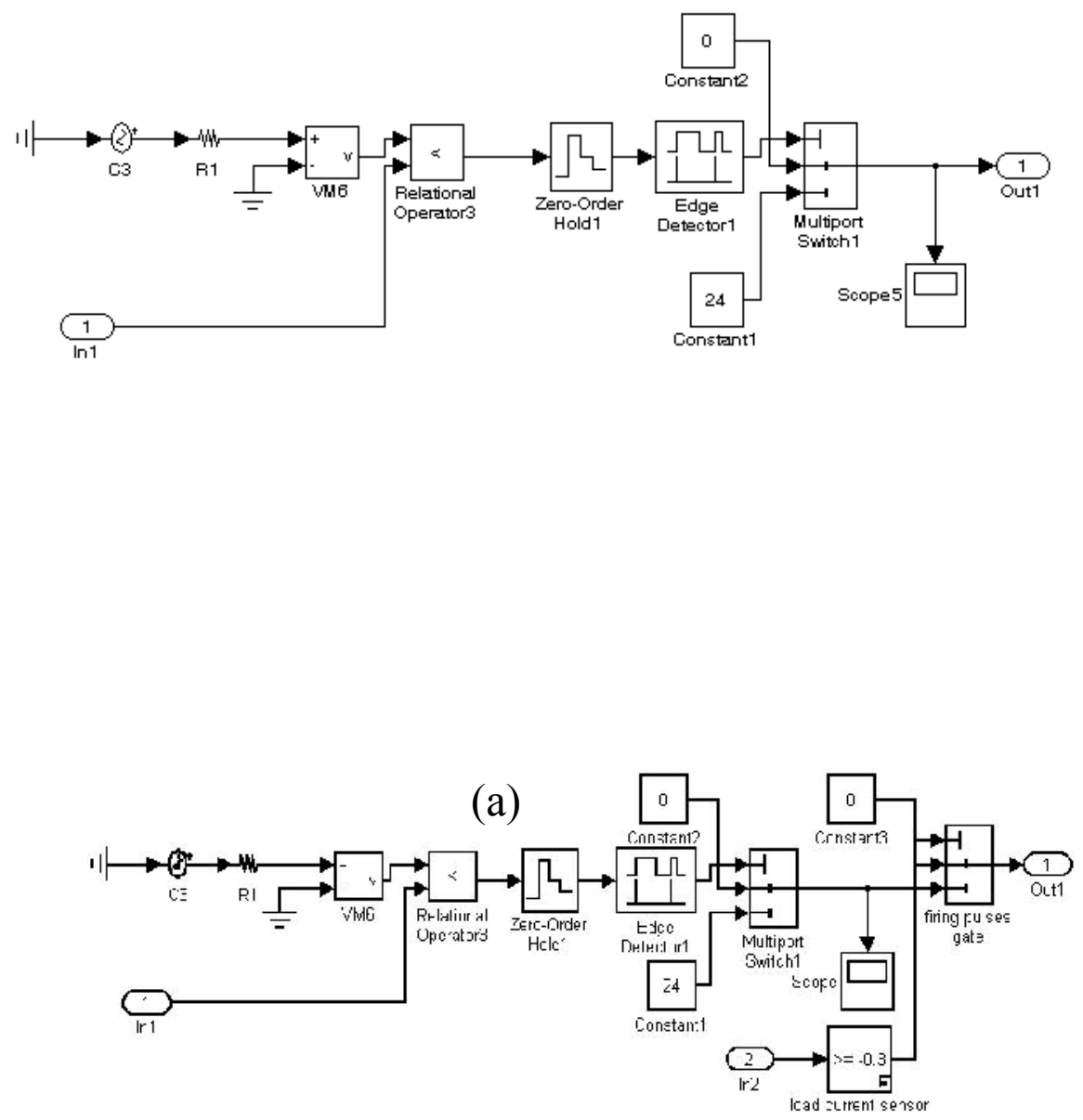

(b)

Fig (3-3): MATLAB-SIMULINK models for single thyristor control circuits a-circulating current cycloconverter. b-semi-circulating current cycloconverter.

\section{4- Results Of Output waveforms:}

The different operation modes of 3-pulse, 6-pulse and 12-pulse cycloconverter systems were carried out. An R-L load was used.

Fig. (4-1) shows output phase voltages and currents for different mades of operation of the 3-pulse cycloconverter.

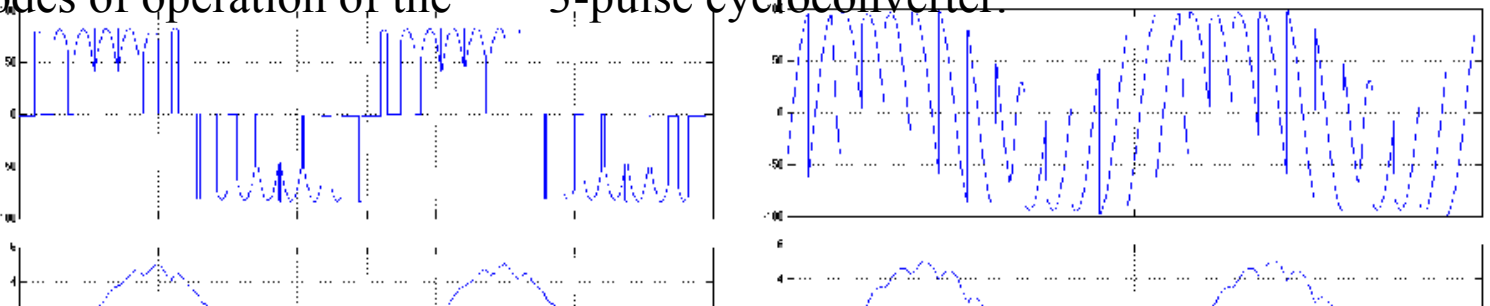


Fig.(4-1): Output phase voltages and currents for 3-pulse cycloconverter with R-L load and $\mathrm{fo}=10 \mathrm{~Hz}$ a- Circulating current mode. b- Semicirculating current mode

Fig. (4-1) shows output phase voltages and currents for different modes of operation of the 3-pulse cycloconverter.

Fig. (4-2) shows output phase voltages and currents for different modes of operation of the 6-pulse bridge cycloconverter.

This type of circuit is commonly used for 3-phase a-c machine loads, since it is usually a simple matter to electrically isolate the 3-phase windings of the machine from one another.

Fig. (4-3) shows the output phase voltages and currents of circulating current 12-pulse bridge cycloconverter.
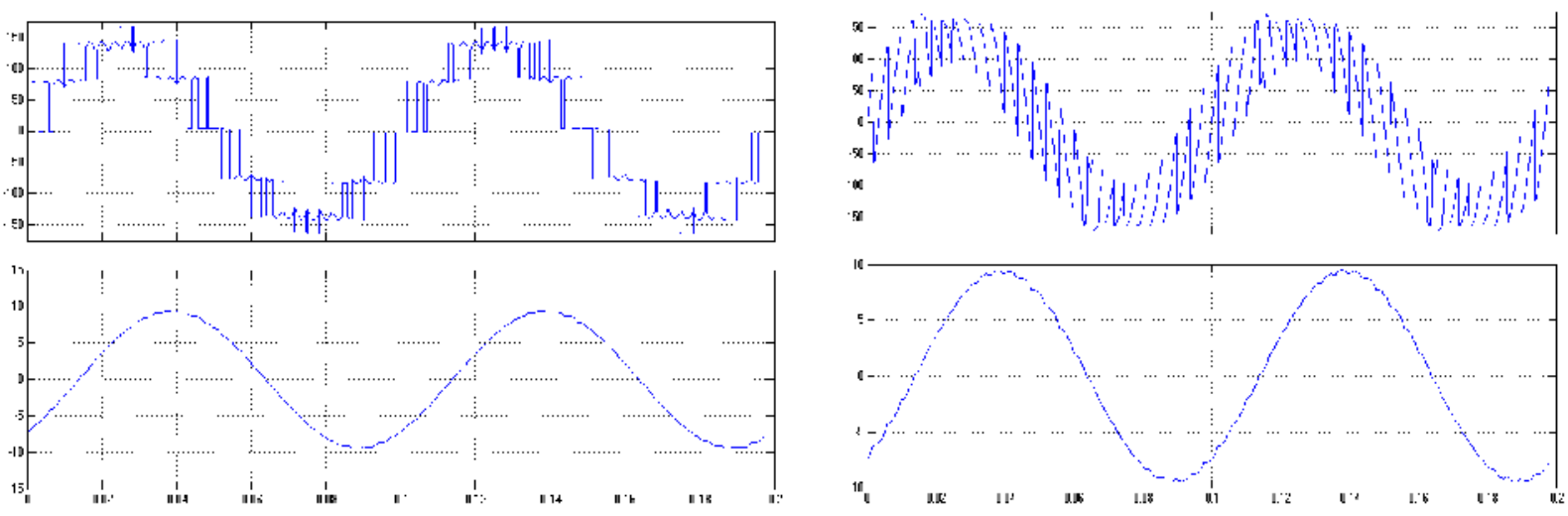
Time(ms)

(a)
Time(ms)

(b)

Fig.(4-2): Output phase voltages and currents for 6-pulse cycloconverter with R-L load and fo $=10 \mathrm{~Hz}$ a- Circulating current mode. b- Semi-

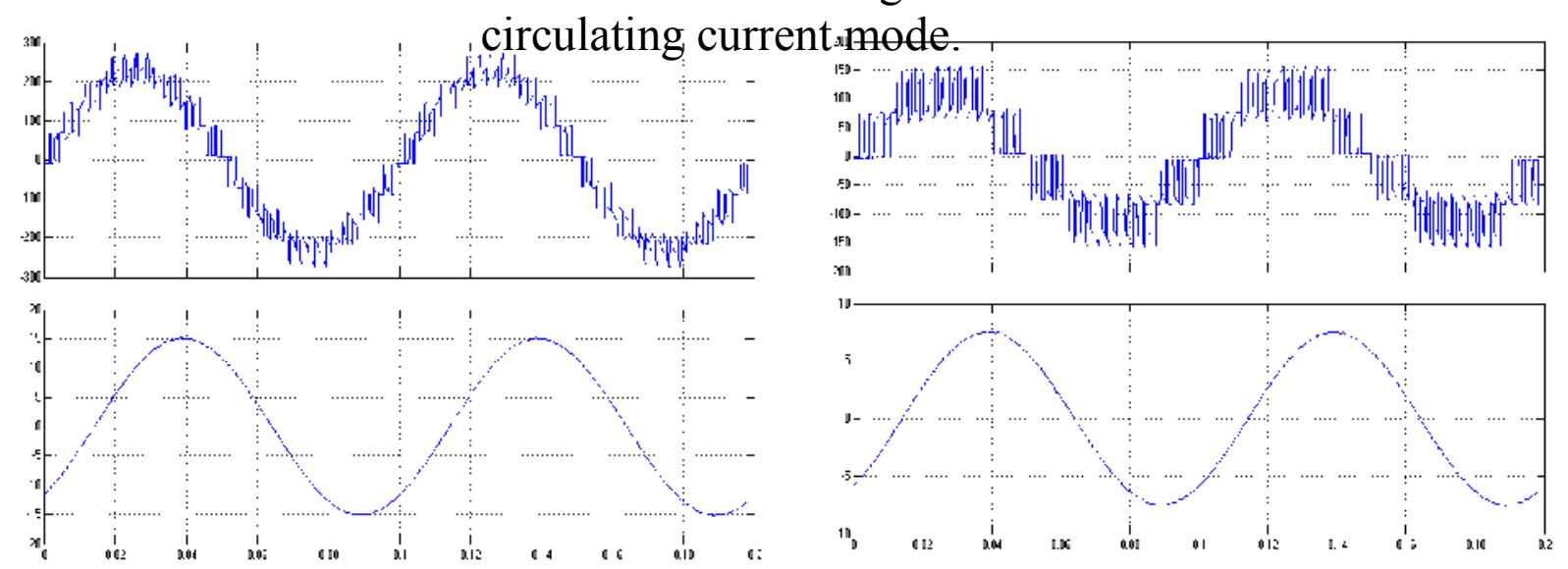

Time(ms)

(a)
Time $(\mathrm{ms})$

(b)

Fig.(4-3): Output phase voltage and current for 12-pulse circulating current cycloconverter a- modulation depth $=0.8 \mathrm{~b}$-modulation depth $=0.4$.

\section{5- Output voltage waveforms spectrum:}

The production of harmonics in the output of a cycloconverter as a result of the process of voltage synthesis is un-avoidable. The direct 
process of frequency changing makes the harmonics functions of both the input and the output frequencies. Thus, the main class of distortion terms constitute beat frequency components having frequencies which are both sum and difference of multiples of both (fo) and (fin). There are several factors affecting the harmonic content of the waveforms. Non circulating current mode of operation produces more complex harmonics than circulating mode of operation due to the zero current distortion. In addition to this, the pulse number effects the harmonic content. A greater number of pulses has less harmonic content. Therefore, a 6-pulse cycloconverter produces less harmonics than a 3-pulse cycloconverter. Moreover, if the output frequency gets closer to the input frequency, the harmonics increase. Finally, low power factor and discontinuous conduction, both contribute to harmonics[3].

The general observed frequency spectrum of the proposed system was found to be:

$$
\begin{aligned}
& \text { foh }=\mid p(2 m-1) * \text { fin } \pm 2 n \text { fo } \mid \\
& \text { foh }=\mid p m \text { fin } \pm(2 n+1) * \text { fo } \mid
\end{aligned}
$$

Where: foh is the harmonic component in the output voltage: $\mathrm{m}$ is any integer from 1 to infinity

$\mathrm{n}$ is any integer from 0 to infinity

In circulating current mode, the two converters are operated simultaneously during the hole output cycle. Thus, it is expected that the harmonics having $(+)$ sign are the same as those with (-) sign in equation 1 and 2, but this is not the same in the semi-circulating mode, as shown in fig. (5-1).
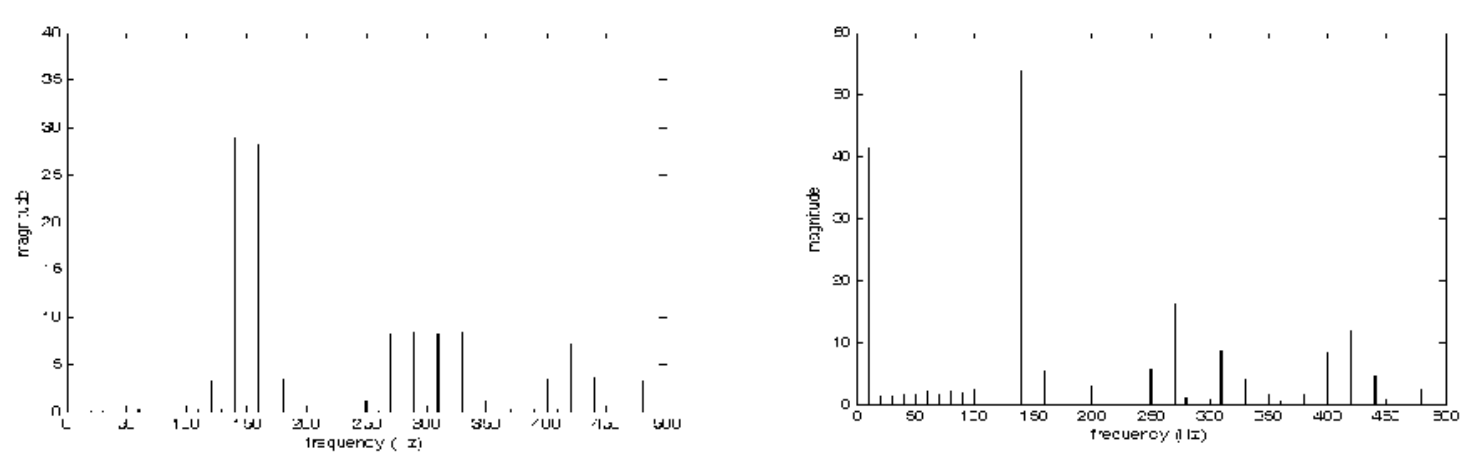
(a)

(b)

Fig.(5-1): The spectrum of the output voltage waveforms of fig.(4-1) a and $b$ respectively

The spectrum for the case of 6-pulse cycloconverter is shown in fig.(5-2). It is obvious that the fundamental component for 6-pulses cycloconverter is grater than with 3-pulse cycloconverter and less other frequency harmonics. And with equations $1 \& 2$ harmonics in 6-pulse cycloconverter will appear around beating frequencies double that with 3 -pulse cycloconverter.
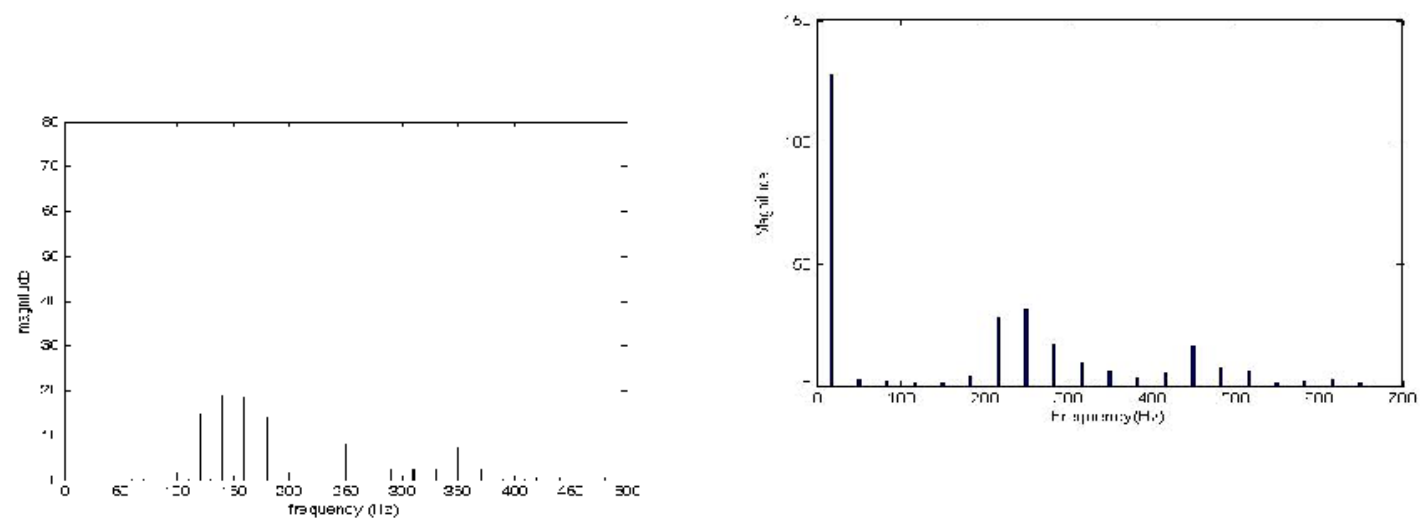

(a)

Fig.(5-2): The spectrum of the output voltage waveforms of fig.(4-2) a and $b$ respectively 
The spectrum of 12-pulse cycloconverter output voltage waveform is shown in fig. (5-3)

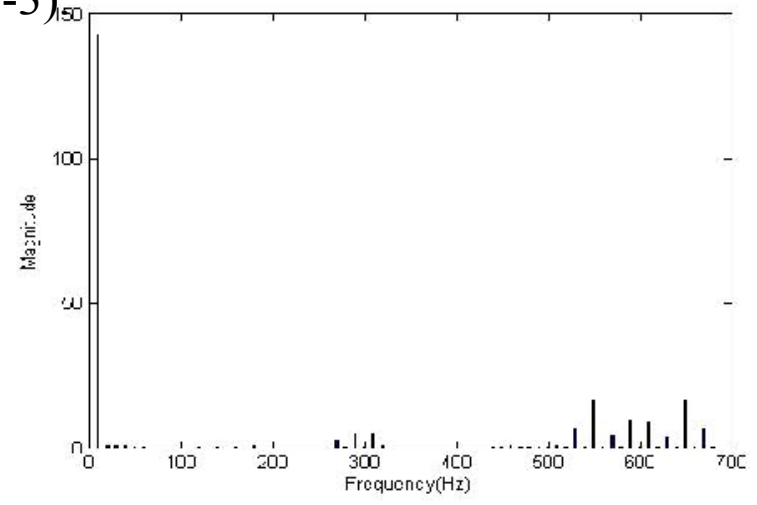

Fig. (5-3): The spectrum of the output voltage waveform of fig. (4-3)b.

\section{6- Feeding an Induction Motor:}

A 3- phase induction motor has been connected as a load unit at the output terminals of the cycloconverter as shown in fig. (6-1) were the MATLAB-SIMULINK model for the complete system has been constructed to test the effeciency and reliability of the continous controlling of the system on the motor speed and characteristics.

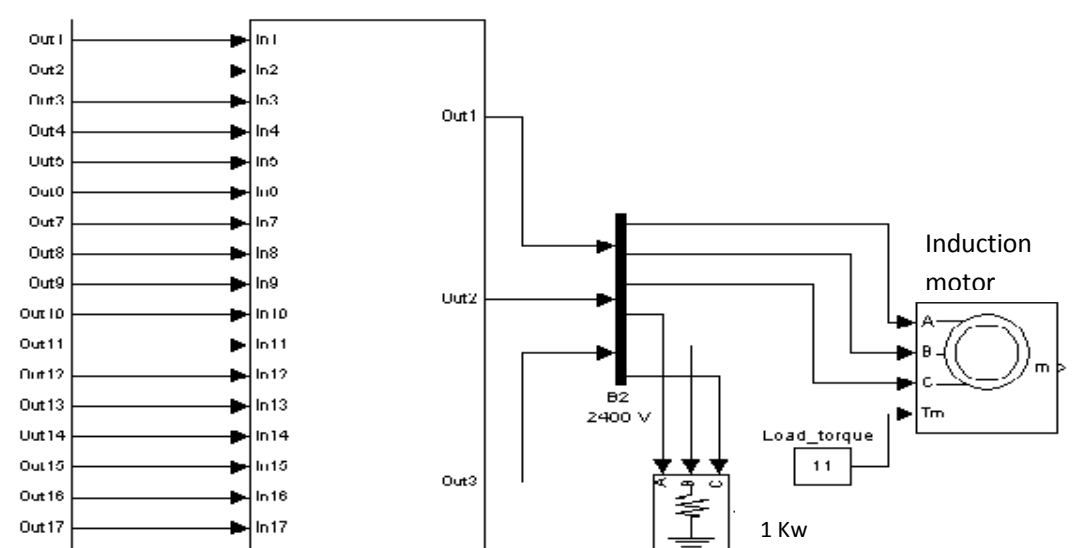


Fig (6-1): MATLAB-SIMULINK model for the complete cycloconverter system feeding an induction motor.

Fig. (6-3) illustrates the starting of the motor then change which takes place in motor speed due to changing the output frequency of the cycloconverter from $(16.667) \mathrm{Hz}$ to $(10) \mathrm{Hz}$, and fig. (6-4) represents the motor torque.

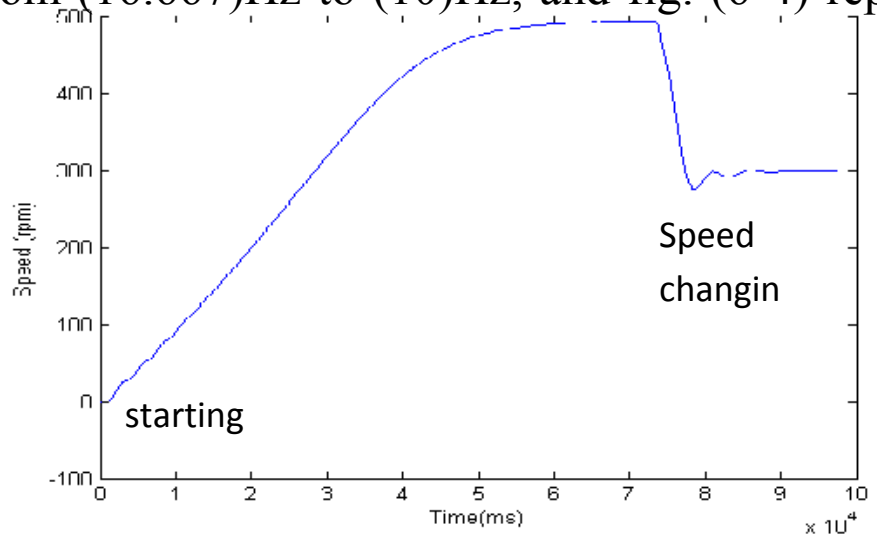

Fig.(6-3): Online control on motor speed due to (starting) and then changing the output frequency.

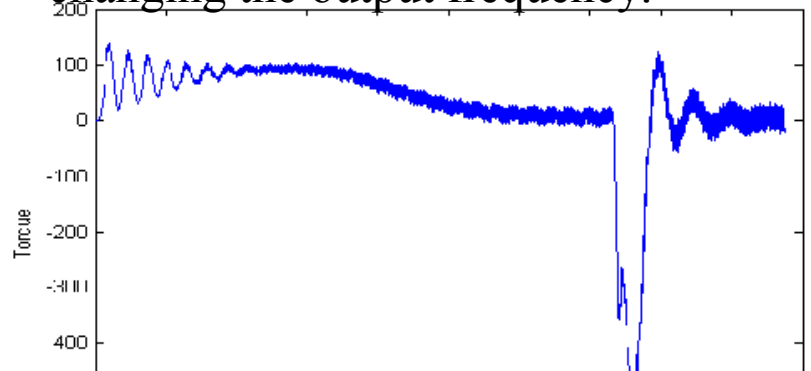


Fig.(6-4): Motor torque during changing the output frequency.

\section{7- Output Power Factor Correction:}

The output power factor has been evaluated by the relationship:

n

$$
\Sigma \mathrm{E}_{\mathrm{Ln}} \mathrm{I}_{\mathrm{Ln}} \cos \varphi_{\mathrm{Ln}}
$$

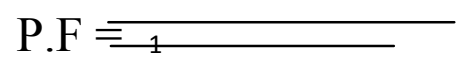

$$
\sqrt{ }\left(\Sigma \mathbf{E}_{\mathbf{L n}}{ }^{2}\right)\left(\Sigma \mathbf{I}_{\mathbf{L n}}{ }^{2}\right)
$$

Where the output voltage and current waveforms are nonsinusoidal as shown in output waveforms results. Therefore both distortion factors of voltage and current should be taken in consideration.

An example to explain the mathmatical analysis for calculation the power factor for inductive load of $(\mathrm{R}=10 \mathrm{ohm}, \mathrm{L}=180 \mathrm{mH})$, at output frequency of $10 \mathrm{~Hz}$. And modulation depth of $\mathrm{r}=0.5$ for a 3-phase to 3phase six pulse cycloconverter. From the spectrum analysis of the output voltage and current waveforms, following harmonic component appears as shown below: 
From equation (3):

To calculate the numerator:

$=\mathrm{E}_{\mathrm{L} 1} \mathrm{I}_{\mathrm{L} 1} \cos \varphi_{\mathrm{L} 1}+\mathrm{E}_{\mathrm{L} 25} \mathrm{I}_{\mathrm{L} 25} \cos \varphi_{\mathrm{L} 25}+\mathrm{E}_{\mathrm{L} 27} \mathrm{I}_{\mathrm{L} 27} \cos \varphi_{\mathrm{L} 27}+\mathrm{E}_{\mathrm{L} 29} \mathrm{I}_{\mathrm{L} 29} \cos \varphi_{\mathrm{L} 29}+$ $\mathrm{E}_{\mathrm{L} 31} \mathrm{I}_{\mathrm{L} 31} \cos \varphi_{\mathrm{L} 31}+\mathrm{E}_{\mathrm{L} 33} \mathrm{I}_{\mathrm{L} 33} \cos \varphi_{\mathrm{L} 33}+\mathrm{E}_{\mathrm{L} 35} \mathrm{I}_{\mathrm{L} 35} \cos \varphi_{\mathrm{L} 35}+\mathrm{E}_{\mathrm{L} 55} \mathrm{I}_{\mathrm{L} 55} \cos \varphi_{\mathrm{L} 55}+$ $\mathrm{E}_{\mathrm{L} 57} \mathrm{I}_{\mathrm{L} 57} \cos \varphi_{\mathrm{L} 57}+\mathrm{E}_{\mathrm{L} 59} \mathrm{I}_{\mathrm{L} 59} \cos \varphi_{\mathrm{L} 59}+\mathrm{E}_{\mathrm{L} 61} \mathrm{I}_{\mathrm{L} 61} \cos \varphi_{\mathrm{L} 61}+\mathrm{E}_{\mathrm{L} 63} \mathrm{I}_{\mathrm{L} 63} \cos \varphi_{\mathrm{L} 63}+$ $\mathrm{E}_{\mathrm{L} 65} \mathrm{I}_{\mathrm{L} 65} \cos \varphi_{\mathrm{L} 65}$

\section{$=\mathbf{2 7 0 . 1}$}

to calculate the denominator:

$$
\begin{aligned}
& =\mathrm{SQR}\left[\left(\mathrm{E}_{\mathrm{L} 1}{ }^{2}+\mathrm{E}_{\mathrm{L} 25}{ }^{2}+\mathrm{E}_{\mathrm{L} 27}{ }^{2}+\mathrm{E}_{\mathrm{L} 29}{ }^{2}+\mathrm{E}_{\mathrm{L} 31}{ }^{2}+\mathrm{E}_{\mathrm{L} 33}{ }^{2}+\mathrm{E}_{\mathrm{L} 35}{ }^{2}+\mathrm{E}_{\mathrm{L} 55}{ }^{2}+\right.\right. \\
& \left.\mathrm{E}_{\mathrm{L} 57}{ }^{2}+\mathrm{E}_{\mathrm{L} 59}{ }^{2}+\mathrm{E}_{\mathrm{L} 61}{ }^{2}+\mathrm{E}_{\mathrm{L} 63}{ }^{2}+\mathrm{E}_{\mathrm{L} 65}{ }^{2}\right) \times\left(\mathrm{I}_{\mathrm{L} 1}{ }^{2}+\mathrm{I}_{\mathrm{L} 25}{ }^{2}+\mathrm{I}_{\mathrm{L} 27}{ }^{2}+\mathrm{I}_{\mathrm{L} 29}{ }^{2}+\mathrm{I}_{\mathrm{L} 31}{ }^{2}+\right. \\
& \left.\left.\mathrm{I}_{\mathrm{L} 33}{ }^{2}+\mathrm{I}_{\mathrm{L} 35}{ }^{2}+\mathrm{I}_{\mathrm{L} 55}{ }^{2}+\mathrm{I}_{\mathrm{L} 57}{ }^{2}+\mathrm{I}_{\mathrm{L} 59}{ }^{2}+\mathrm{I}_{\mathrm{L} 61}{ }^{2}+\mathrm{I}_{\mathrm{L} 63}{ }^{2}+\mathrm{I}_{\mathrm{L} 65}{ }^{2}\right)\right] \\
& =\sqrt{(180.4)^{2} \times(5.45)^{2}} \quad=\mathbf{9 8 3 . 1} \\
& \therefore \quad \text { P.F }=\underline{270.1}=\underline{\mathbf{0 . 2 7}}
\end{aligned}
$$

Table (1) shows the output power factor from diferent values of output frequency and modulation depth. While table (2) represents power factor values for diferent number of cycloconverter pulses.

Table(1): Output power factor for different output frequency and modulation depth for 6-pulse cycloconverter with R-L load.

\begin{tabular}{|l|c|c|c|c|c|c|}
\hline $\begin{array}{l}\text { Modulation Depth } \\
(\mathrm{r})\end{array}$ & 1.0 & 0.9 & 0.8 & 0.7 & 0.6 & 0.5 \\
\hline $\begin{array}{l}\text { P.F for output freq.= } \\
\text { 5Hz }\end{array}$ & 0.6 & 0.56 & 0.5 & 0.45 & 0.41 & 0.38 \\
\hline
\end{tabular}




\begin{tabular}{|l|l|l|l|l|l|l|}
\hline $\begin{array}{l}\text { P.F for output freq. } \\
10 \mathrm{~Hz}\end{array}$ & 0.44 & 0.41 & 0.38 & 0.34 & 0.3 & 0.27 \\
\hline
\end{tabular}

Table(2): Output power factor for different modulation depth and number of pulses at output frequency $=10 \mathrm{~Hz}$.

\begin{tabular}{|c|c|c|c|c|c|c|}
\hline $\begin{array}{c}\text { Modulation Depth } \\
\text { (r) }\end{array}$ & 1.0 & 0.9 & 0.8 & 0.7 & 0.6 & 0.5 \\
\hline P.F for 12-pulse & 0.57 & 0.52 & 0.47 & 0.43 & 0.4 & 0.37 \\
\hline P.F for 6-pulse & 0.44 & 0.41 & 0.38 & 0.34 & 0.3 & 0.27 \\
\hline
\end{tabular}

For output power factor correction, capacitors have been connected in parallel with the load. To find the value of the capacitor, following relationship has been used:

$C=\frac{I_{l} \sin \varphi}{w E}$

Where: $\quad \mathrm{I}_{\mathrm{L}}$ is the load current (rms)

$\varphi$ is the angle between the load current and voltage.

$\mathrm{E}$ is the load voltage (rms)

Table (3) repersents power factor values for the same conditions of table (1) after adding correction capacitors.

Table(3): Output power factor after connecting correction capacitors for six-pulse cycloconverter. 


\begin{tabular}{|c|c|c|c|}
\hline Output Frequency & $5 \mathrm{~Hz}$ & $10 \mathrm{~Hz}$ & $16.667 \mathrm{~Hz}$ \\
\hline P.F & 0.92 & 0.9 & 0.73 \\
\hline
\end{tabular}

\section{Conclusions:}

Control circuit for individual thyristor has been constructed using SIMULINK model, separation of control circuits provides high flexibility for the hole system operation, The cycloconverter will operate satisfactory with any number of pulses. Finally this number of pulses will not complicate the control circuits, because it will just increases the number of these control circuits. Increasing number of pulses will improve the cycloconverter output waveforms and will dicrease the harmonic component valuse, which means improving of output power factor. An induction motor has been connected under on-line control to test the motor response for cycloconverter mechanism. Results of present simulation has been compared with practical results and shows good agreement with them, which indicates that the system is reliable.

\section{References:}

[1]. Pelly, B.R, "Thyristor Phase-Controlled Converters and Cycloconverters", New-York, (Wiley-Interscience), 1971.

[2]. Mohammed, B.A, "Microprocessor Based Control of Cycloconverters", M.Sc. Thesis, University of Mosul, Iraq, December 1990.

[3]. Zhenyuan Wang and Yilu Liu, "Modeling and Simulation of a Cycloconverter Drive System for Harmonic studies", IEEE 
transaction on industrial electronics, Volume 47, Number 3, June 2000 .

[4]. W. Shepherd and P. Zand, "Energy flow and power factor in nonsinusoidal circuits" Cambridge University Press 1979.

[5]. Miyazawa, S. Nakamura, F. and Yamada, N. "Effective Approximation Suitable for the Control Algorithm of Microprocessor Based Cycloconverter", IEEE Transaction, August 1988. 